\title{
LAS JUNTAS LITERARIAS: LEGADO DE LA CIRUGÍA ILUSTRADA
}

\author{
Nuria Pérez-Pérez, Antonio Sitges-Serra
}

Dirección para correspondencia:
A. Sitges-Serra
Departamento de Cirugía
Hospital del Mar
P. Marítim, 25-29
08003 Barcelona
e-mail: asitges@imas.imim.es
e-mail: nuriap.perez@upf.edu

Tel. 932483208

Publicado por Elsevier España, S.L. Todos los derechos reservados EN: Cirugía Española, doi:10.1016/j.ciresp.2009.05.006 
Si el progreso del conocimiento en la esfera biomédica procede en la actualidad en gran medida del estudio del código genético, entendido como el "libro de la vida", en el siglo XVIII cirujanos y médicos, a menudo fuertemente enfrontados profesionalmente, apelaban a otras metáforas, también referidas al lenguaje, para referirse a la fuente primaria de conocimiento. Los cirujanos ilustrados concebían el cuerpo humano como el libro sobre el cual aprender el origen profundo de la vida, la salud y la enfermedad. A su vez, los médicos, consideraban una necesidad epistemológica, una fuente legítima de conocimiento y progreso científico, la compilación de casos clínicos y el aprendizaje de esas primeras series de observaciones considerándolas como la principal fuente del saber clínico.

Arrancando pues, en aquellos "siglos de la Luces", la profesión médica inicia una larga tradición de recogida meticulosa y puesta en común de las observaciones clínicas y, como consecuencia de las mismas, una larga tradición de investigación observacional aplicada al estudio de las causas y el tratamiento las enfermedades. Sin embargo, son escasas las referencias documentadas sobre los inicios de este tipo de actividad a la vez comunicativa y científica en nuestro entorno. Posiblemente, las Juntas Literarias celebradas en los Reales Colegios de Cirugía, entre ellos el de Barcelona, constituyan una de las primeras pruebas documentales de lo que en terminología contemporánea denominaríamos "congreso" "seminario" o "reunión científica".

\section{EI Real Colegio de Cirugía de Barcelona (1760-1843)}

La actividad de las Juntas Literarias no se puede comprender de forma cabal sin recordar, brevemente, la fundación del Real Colegio de Cirugía de Barcelona. Ésta tuvo lugar años después de que con el Decreto de Nueva Planta (1714) la monarquía borbónica española clausurara las universidades catalanas y fundara la Universidad de Cervera (1740). El nuevo Colegio quedó ubicado en unos terrenos cercanos al antiguo Hospital de Santa Creu que en aquel entonces, y desde el s. XV, era el centro sanitario de referencia de la ciudad de Barcelona. Del mismo modo que hoy en día la docencia se aproxima a la práctica clínica, el conjunto monumental integrado por el Real Colegio de Cirugía, el antiguo Hospital de Santa Creu (1401) y la Casa de la Convalecencia (1629), 
escenificaba un espacio común en el que se concebía por primera vez como un todo indisoluble la docencia, la investigación y la práctica clínica.

El Real Colegio de Cirugía de Barcelona cambió con frecuencia de denominación. La Guerra de la Independencia (1808-1816) supuso un importante paréntesis en su actividad. Pasada la contienda, otros sucesos marcaron su destino siendo uno de los más significativos la reunión del Colegio con la Academia Médico-Práctica, el Colegio de Farmacia San Victoriano y la Facultad de Medicina de la Universidad de Cervera, en lo que se denominó Escuela Especial del Arte de Curar que fue inaugurada el 7 de febrero de 1822. Llegó a funcionar apenas unos meses pero unos años más tarde, en 1827, se reunieron los estudios de Cirugía y Medicina en el Colegio de Medicina y Cirugía, una única institución académica que otorgaba el grado de doctor en medicina y cirugía. Como afirma Usandizaga, se había alcanzado una meta tras recorrer un largo camino: la unificación de la Cirugía y la Medicina. Cuando la Universidad de Barcelona fue reinstaurada en 1842, el edificio del antiguo Real Colegio de Cirugía, que celebrará el próximo año 2010 su 250 aniversario, albergó la Facultad de Ciencias Médicas hasta que, en 1906, se trasladó a la nueva sede de la calle de Casanova donde actualmente se ubica la Facultad de Medicina de la Universidad de Barcelona. Más tarde acogería durante un tiempo la Escuela de Magisterio. Desde 1929 hasta hoy en día, el edificio neoclásico es la sede de la Reial Acadèmia de Medicina de Catalunya.

Los programas docentes establecidos en los nuevos colegios de cirugía españoles, impulsados desde la Corte de Madrid por el cirujano catalán y antiguo profesor del colegio de Barcelona Antoni de Gimbernat Arbós, deben ser considerados como el inicio de una nueva concepción de la profesión. El programa académico que se instauró en los colegios de cirugía españoles (Cádiz, Barcelona y Madrid) difería sustancialmente de la formación gremial tradicional de cirujanos y barberos, especialmente en lo que podríamos denominar estudio de "las ciencias básicas". En efecto, el análisis de los contenido de las Juntas Literarias del Colegio de Barcelona desde esta perspectiva ha revelado por primera vez que los físicos-cirujanos de los reales colegios se interesaban, además de por la cirugía propiamente dicha, por la anatomía, la fisiología, la química, la física experimental y la botánica, es decir, por las ciencias básicas de la época. 


\section{Los documentos originales}

Una importante serie documental manuscrita y hasta hoy poco estudiada: las Juntas Literarias del Real Colegio de Cirugía de Barcelona, certifica los inicios de la práctica de la cirugía moderna española y la puesta en común de las primeras experiencias en este terreno. Manuel Usandizaga fue el primer estudioso que destacó la importancia de estos manuscritos de temática científica. De estas reuniones se conservan en la biblioteca de la Universidad de Barcelona unos 200 manuscritos - o "actas"- a los que hay que añadir sus respectivas censuras, el más antiguo data del $1765 \mathrm{y}$ el último del 1835. La serie documental presenta interrupciones temporales que coinciden con los períodos políticamente conflictivos que sin duda hubieron de repercutir en el normal funcionamiento del colegio.

\section{Las Juntas Literarias}

Las ordenanzas por las que se regían los colegios de cirugía españoles en el s. XVIII se anunciaron públicamente por primera vez en la Gazeta de Barcelona, el 16 de octubre de 1764, en los siguientes términos: Estatutos y ordenanzas generales que S.M. manda observar a los Colegios y comunidades de cirujanos, establecidos en Barcelona, Cádiz y en todo el Principado de Cataluña para la enseñanza de la Cirugía, exámenes de los profesores y un gobierno económico (Barcelona, 1764). En ellas, se establecía el requerimiento de la celebración de unas sesiones periódicas, las "juntas literarias", seminarios públicos en que los profesores del colegio exponían los temas que suscitaban mayor interés en cada momento y que iban más allá de los programas docentes y los libros de texto. Las juntas literarias significaron una primera actividad de transmisión del conocimiento -a la vez que un nuevo método pedagógico- dirigida a los alumnos y al claustro de profesores pero abiertas también al público lego. Las Ordenanzas publicadas en 1795, daban mayor detalle de su celebración:

"En los jueves de cada semana por la tarde, y si éste fuese festivo, en el inmediato que no lo fuera, concluidas las lecciones de Cátedra, se celebrará Junta ordinaria en la sala destinada para ellas, y siendo pública, estará abierta media hora antes de empezarse el acto literario, para permitir la entrada a cualquiera persona decente, aunque no sea facultativo; pero tendrán particular 
cuidado los Catedráticos de que asistan todos los discípulos, de cualquier clase que sean, por la utilidad e instrucción que les pueda resultar: y se pondrán asientos separados para los sugetos (sic) de distinción, y graduados de cualquier Facultad; más si asistiere algún Profesor de Cámara propietario ú honorario que no tuviese empleo en el Colegio, se le dará asiento a continuación de los Maestros que componen la Junta".

Así pues, bajo el nombre de Juntas Literarias, se celebraban con regularidad en el colegio barcelonés sesiones públicas de carácter científico que reunían a profesores, alumnos y público en general, a propósito de la lectura, exposición y crítica de “observaciones clínicas” o memorias.

En cuanto a la manera de proceder, el director del colegio designaba periódicamente a los profesores encargados de realizar la memoria u "observación" y su crítica o "censura". Ambas quedaban inscritas para su lectura en "junta literaria". Un tercer documento recogía breves comentarios de las observaciones realizadas por parte de los profesores del colegio. La crítica o "censura" de la observación correspondiente tenía lugar 15 días después de haberse presentado la disertación objeto de comentario.

\section{Los textos y los temas}

Estos manuscritos, escritos en castellano según prescribían las ordenanzas, poseen una estructura determinada a modo de los resúmenes estructurados contemporáneos: título, breve introducción, fecha, autoría, cuerpo principal con el tema a exponer y conclusión. La censura o crítica, igualmente manuscrita, constaba asimismo de título, fecha, autoría $\mathrm{y}$, siempre, en primer lugar, reproducía la observación sometida a crítica. Aunque las ordenanzas preveían su publicación, no llegaron nunca a ver la luz por carecer de suficiente interés según anotaron sus revisores años más tarde.

Los temas sobre los que tratan las juntas literarias son múltiples y de una riqueza inestimable. Contrariamente a lo que en un principio cabría pensar, no se centraban exclusivamente en la lesión anatomopatológica como indicio de la enfermedad ni se restringían a temas propios de la cirugía, tales como heridas por armas de fuego, sangrías, trepanación o métodos operatorios comunes en la época como la operación de 
la talla vesical, las amputaciones de miembros o las herniorrafias. Las juntas literarias reflejan también otros aspectos insospechados, muy relacionados con la nueva ciencia desarrollada a partir de la química moderna de Lavoisier; por ejemplo, el estudio de la composición de los aires -la denominada química neumática- y su posible aplicación a la fisiología animal. Algunas aplicaciones de la química a la salud pública fomentaron el desarrollo de mejores compuestos para las fumigaciones en época de epidemias (fiebre amarilla, viruela, etc.) o nuevos compuestos para paliar infecciones venéreas como la sífilis. Por ejemplo, la observación titulada Disertación sobre el uso de los globos aerostáticos aplicados a la medicina (Bover, 1800) es una junta literaria que propone llegar al oxígeno atmosférico de altura como tratamiento de algunas enfermedades neurológicas. La documentación estudiada ha puesto de manifiesto que, a finales del siglo XVIII, la química y la física experimental estaban muy presentes en las disertaciones del colegio barcelonés.

\section{Controversias de la época}

Como en las reuniones científicas contemporáneas, uno de los objetivos de las disertaciones era poner de relieve las controversias científicas del momento como, por ejemplo, los debates que aparecían en las revistas especializadas (Annales de Chimie) y que distaban todavía de aparecer en los libros de texto. A propósito de una de las más famosas controversias sobre el origen del fluido eléctrico animal, que enfrentaron a los seguidores de Galvani por un lado y de Volta por otro, varias juntas literarias -Discurso sobre el galvanismo (Bover, 1802); Sobre el trismus traumático (Cibat, 1798) o Sobre la fibra muscular (Bover, 1806)- y sus respectivas censuras, se hicieron eco del debate. El interés de los profesores del colegio barcelonés por la física experimental estuvo siempre en función de sus posibilidades terapéuticas y de su posible aplicación a determinadas enfermedades. Antonio Cibat, profesor de física experimental del colegio, dejó constancia en su obra escrita de la importancia de las juntas literarias en sus investigaciones sobre el galvanismo (Continuación de los ensayos experimentales con convulsiones, 1806). Este científico ilustrado, miembro de la Real Academia de Ciencias de Barcelona y miembro de diversas sociedades científicas europeas, intentó, 
aunque sin éxito, reproducir los principales experimentos realizados sobre la electricidad en organismos vivos por Galvani, Volta, Humboldt o Crève.

Otra interesante disertación que muestra la importancia de esta valiosa serie documental, versa sobre la introducción de la vacuna en nuestro país. Se estima que en Europa, en el siglo XVIII, la viruela ocasionaba de doscientas a seiscientas mil víctimas al año y era responsable del $25 \%$ de la mortalidad, fundamentalmente infantil. El Real Colegio de Barcelona debatió en junta literaria la introducción y los beneficios de la vacuna entre la población, poco después de que Jenner hiciera público su descubrimiento. La correspondiente memoria Disertación sobre el uso de la vacuna (Marturià, 1 de mayo de 1801) y la correspondiente crítica Censura de la disertación que leyó de la vacuna el Dr. Dn Esteban Marturiá (Pozo, 1801) aportan datos de experimentos realizados con niños -a modo de "ensayos clínicos" y salvando las distancias temporales- que fueron publicados en revistas especializadas para probar la eficacia de la vacuna. Algunos de estos experimentos consistieron en realizar una doble inoculación, primero la procedente de la viruela vacuna y a continuación una inoculación con viruela humana, para comprobar si realmente se había desarrollado la buscada inmunidad. Problemas metodológicos relacionados con el desconocimiento que se tenía de la existencia de los virus y la falta de la debida esterilización del material utilizado confundían a menudo los resultados obtenidos.

\section{Conclusión}

Las juntas literarias celebradas en el Real Colegio de Cirugía de Barcelona (1760-1843) constituyen probablemente la primera actividad probada de forma documental destinada a la formación continuada de los cirujanos en ejercicio clínico y docente en Cataluña. Propiciaron una actualización de los conocimientos científicos más relevantes para la Medicina durante la Ilustración y la creación de un espacio de comunicación que fomentó el debate público sobre el progreso científico y los temas más candentes del momento en materia de medicina, cirugía y ciencias afines. Constituyen, pues, una referencia histórica indiscutible en el campo de la formación continuada y la crítica científica que por un lado nos honra y por otro nos estimula a cumplir nosotros mismos con la obligación del estudio y el debate honrado. 


\section{Núria Pérez-Pérez}

Centro de Historia de la Ciencia (CEHIC) de la UAB

Observatorio de la Comunicación Científica (OCC) de la UPF

\section{Antonio Sitges-Serra}

Presidente de la Societat Catalana de Cirurgia 


\section{BIBLIOGRAFÍA}

Ferrer D. Biografía de Pedro Virgili: fundador, restaurador de la cirugía en España, Barcelona, Colegio Oficial de Médicos. 1963.

Massons JM'. Història del Reial Col·legi de Cirurgia de Barcelona, Barcelona, Fundació Uriach 1838. 2002

Pérez-Pérez N. Anatomia, química i fisica experimental al Reial Col·legi de Cirurgia de Barcelona (1760-1808), Barcelona, Universitat Autònoma de Barcelona, 2007, http://www.tesisenxarxa.net/TDX-1203107-162239/index.html.

Usandizaga Soraluce M. Historia del Real Colegio de Cirugía de Barcelona. Barcelona, Instituto Municipal de Historia de Barcelona. 1964

Usandizaga Soraluce M. Las Juntas Literarias del Real Colegio de Cirugía de Barcelona, Barcelona. 1956

Zarzoso A. L'exercici de la medicina a la Catalunya de la Il·lustració, Manresa, Arxiu Històric de les Ciències de la Salut. 2006. 